\title{
Glycated hemoglobin Alc-based adjusted glycemic variables in patients with diabetes presenting with acute exacerbation of chronic obstructive pulmonary disease
}

\author{
This article was published in the following Dove Press journal: \\ International Journal of COPD \\ 3 July 2017 \\ Number of times this article has been viewed
}

\author{
Chih-Jen Yang' \\ Wen-I Liao' \\ Zun-Cheng Tang ${ }^{2}$ \\ Jen-Chun Wang' \\ Chien-Hsing Lee ${ }^{3}$ \\ Wei-Chou Chang ${ }^{4}$ \\ Chin-Wang $\mathrm{Hsu}^{5,6}$ \\ Shih-En Tang ${ }^{7}$ \\ Shih-Hung Tsai'
}

'Department of Emergency Medicine, Tri-Service General Hospital, National Defense Medical Center, ${ }^{2}$ Department of Biological Imaging and Radiological Science, National Yang-Ming University, ${ }^{3}$ Division of Endocrinology and Metabolism, Department of Internal Medicine, Tri-Service General Hospital, National Defense Medical Center, ${ }^{4}$ Department of Radiology,

Tri-Service General Hospital, National Defense Medical Center, ${ }^{5}$ Department of Emergency Medicine, School of Medicine, College of Medicine, ${ }^{6}$ Department of Emergency and Critical Medicine, Wan Fang Hospital, Taipei Medical University, ${ }^{7}$ Division of Pulmonary and Critical Care, Department of Internal Medicine, TriService General Hospital, National Defense Medical Center, Taipei, Taiwan

Correspondence: Shih-Hung Tsai Department of Emergency Medicine, Tri-Service General Hospital, National Defense Medical Center, Number 325, Section 2, Cheng-Kung Road, Taipei, Taiwan

Tel +886 2879233 I I ext I 2893

Email tsaishihung@yahoo.com.tw
Abstract: Acute hyperglycemia is a common finding in patients presenting to emergency departments (EDs) with acute exacerbation of chronic obstructive pulmonary disease (AECOPD). Several studies have argued against the association between hyperglycemia at admission and adverse outcomes in patients with diabetes and an acute illness. Recent studies have shown that glucose-related variables (eg, glycemic gaps and stress hyperglycemia ratios) that are adjusted for glycated hemoglobin levels can indicate the severity of a variety of diseases. The objective of this study was to assess whether these hemoglobin A1c (HbA1c)-based adjusted average glycemic variables were associated with unfavorable outcomes in patients admitted to a hospital with AECOPD. We found that 1) pulmonary infection is a major risk factor for AECOPD; 2) a higher glycemic gap and modified stress hyperglycemia ratio were associated with the development of acute respiratory failure (ARF) in patients with diabetes admitted to an ED because of AECOPD; and 3) the glycemic gap and modified stress hyperglycemia ratio had superior discriminative power over acute hyperglycemia and $\mathrm{HbA} 1 \mathrm{c}$ for predicting the development of ARF, although the HbAlc-adjusted glycemic variables alone were not independent risk factors for ARF.

Keywords: chronic obstructive pulmonary disease, diabetes mellitus, acute respiratory failure, glycated hemoglobin, hyperglycemia, glycemic gap, stress hyperglycemia ratio

\section{Introduction}

Approximately $10 \%$ of patients with diabetes mellitus (DM) have concomitant chronic obstructive lung disease (COPD), ${ }^{1,2}$ and hyperglycemia occurs in $89 \%$ of patients with COPD during acute respiratory failure (ARF) requiring mechanical ventilation. One of the most important risk factors for hyperglycemia is a premorbid diagnosis of DM. ${ }^{3,4}$ Patients with DM and acute exacerbation of COPD (AECOPD) frequently (50\%-80\% of patients) presented with hyperglycemia during their hospital stay and experienced longer hospital stays and higher mortality rates compared with patients without DM. ${ }^{5}$ Stress-induced hyperglycemia $(\mathrm{SIH})$ is common in patients with critical illnesses. ${ }^{6} \mathrm{SIH}$ is attributed to the presence of excess levels of counter-regulatory hormones and anti-inflammatory cytokines and increased gluconeogenesis and hepatic insulin resistance. ${ }^{7,8}$ Hypoxia acutely causes glucose intolerance, and a factor that likely mediates this effect is an elevated release of epinephrine. ${ }^{9}$ Recent evidence suggests that DM can worsen the progression and prognosis of COPD because of the direct effects of hyperglycemia on lung physiology, inflammation, or bacterial infection 
susceptibility. ${ }^{10}$ Although acute hyperglycemia is generally believed to promote worse outcomes in a variety of acute illnesses, studies have reported inconsistent results regarding the correlation between hyperglycemia and adverse outcomes in acutely ill patients with pre-existing DM.

Recent studies have shown that several hemoglobin A1c (HbA1c)-adjusted glycemic variables, including an elevated glycemic gap and the stress hyperglycemia ratio, which controls baseline blood glucose levels, are better biomarkers for identifying patients at a higher risk of certain critical illnesses. ${ }^{11-15}$ Nonetheless, few studies have applied HbA1c-based glycemic variables to assess disease severity and outcomes in patients with DM and AECOPD. We hypothesize that $\mathrm{HbA} 1 \mathrm{c}-$ based adjustments of acute hyperglycemiarelated variables are associated with the severity of AECOPD. The aim of the present study was to explore whether three HbAlc-based adjustments of hyperglycemia-related variables were correlated with adverse outcomes in patients presenting to an emergency department (ED) with AECOPD.

\section{Materials and methods}

\section{Patients}

We conducted a retrospective observational study of consecutive patients admitted for COPD between January 1, 2013, and November 31, 2015. The institutional review board for human investigations of a tertiary referral medical center (the Tri-Service General Hospital in this study) approved this study and waived the requirement for informed consent because the medical records were de-identified, and the study was retrospective in nature. The methods were in accordance with the approved guidelines. Patients with COPD were identified by searching for the International Classification of Diseases (9th revision) codes 490-492, 494, and 496. The identified patients were then manually reviewed to select only those patients with COPD who also had blood glucose level data from their initial presentation and $\mathrm{HbA} 1 \mathrm{c}$ level data within 1 month before or immediately after their admission. Patients were excluded if they were younger than 18 years old, had incomplete data, presented with hypoglycemia (blood glucose $<70 \mathrm{mg} / \mathrm{dL}$ ), were diagnosed with diabetic ketoacidosis or a hyperosmolar hyperglycemic state, received a blood transfusion, or had obvious patch opacity on their chest radiography. We retrospectively collected patients' medical records to determine age, gender, underlying comorbidities (including coronary artery diseases, chronic kidney disease, congestive heart failure, cerebrovascular accident, and malignancy), and laboratory data, including the blood glucose level upon initial presentation, the $\mathrm{HbA1c}$ level (measured within 1 month before or after admission), and the duration of the hospital stay. Smoking was defined as ever-smoking. DM was considered present if a patient had been discharged from a hospital with a diagnosis of type 1 or type $2 \mathrm{DM}$, had at least one prescription for insulin or an oral antidiabetic agent, and/or had an HbAlc level of $6.5 \%$ in the preceding 2 months. AECOPD was defined as an acute change in symptoms from baseline dyspnea, coughing, and/or sputum production that was beyond normal day-to-day variation. All the medical records were reviewed retrospectively to establish classifications of COPD using the Global Initiative for Chronic Obstructive Lung Disease (GOLD) guidelines. We retrospectively assessed the symptoms, degree of airflow limitation, and risk of exacerbations to classify the patients into GOLD A, B, C, and D categories. The patients were further classified into two groups: patients in the GOLD C and $\mathrm{D}$ categories, who were considered the high-risk group, and patients in the GOLD A and B categories, who were classified as the low-risk group. Patients who were treated with antibiotics because of the presence of purulent sputum during an exacerbation were considered to have a pulmonary infection. ${ }^{16} \mathrm{ARF}$ was defined as severe dyspnea, respiratory distress, hypoxemia (arterial oxygen partial pressure $<60 \mathrm{mmHg}$ ), or hypercapnia (arterial carbon dioxide partial pressure $>60$ $\mathrm{mmHg}$ ) on room air, or a requirement of noninvasive or invasive mechanical ventilation.

\section{Determination of the blood glucose levels and $\mathrm{HbAl}$ c-based adjusted glycemic variables}

The blood glucose level on admission was defined as the level determined within 20 minutes after admission to the ED with AECOPD. HbA1c assays were performed using a high-performance liquid chromatography system (Primus CLC 385; Primus Corporation, Kansas City, MO, USA) in the central laboratory. The following formula was used to convert $\mathrm{HbA} 1 \mathrm{c}$ levels to the estimated A1c-derived average glucose (ADAG) levels: $28.7 \times \mathrm{HbA1c}-46.7 .{ }^{17}$ The glycemic gap, which represents changes in blood glucose levels during the index event, was calculated from the glucose level at ED admission minus the ADAG level. The stress hyperglycemia ratio was calculated from the blood glucose level at ED admission divided by the ADAG level, ${ }^{15}$ whereas the modified stress hyperglycemia ratio was the blood glucose level at ED admission divided by the $\mathrm{HbA} 1 \mathrm{c}$ value.

\section{Statistical analysis}

Continuous data are expressed as the mean \pm standard deviation and were analyzed using a two-tailed Student's $t$-test. Categorical data are expressed as frequencies (\%) and were evaluated using the chi-square or Fisher's exact test. A one-way 
analysis of variance was used to assess the significance of various characteristics, laboratory data, and adverse outcomes. A post hoc analysis was performed using the Bonferroni test. The correlations between the HbAlc-based adjusted glycemic variables and COPD classification were evaluated using the Spearman's rank correlation coefficient (r). A receiver-operator characteristic (ROC) curve was plotted to analyze the discriminative power of the predictive tools, and the area under the ROC (AUROC) curve and its 95\% confidence interval were than calculated. Univariable and multivariable regression analyses were performed to identify the risk factors associated with the development of adverse outcomes. Variables with $P$-values $<0.05$ in the univariable analysis were included in the multivariable regression analysis. The data were analyzed using the Statistical Package for the Social Sciences version 22.0 statistical software (SPSS, Inc., Chicago, IL, USA) and MedCalc statistical software (MedCalc Software, Ostend, Belgium), and differences with $P$-values $<0.05$ were considered statistically significant.

\section{Results}

\section{Demographic data and clinical outcomes}

We initially identified 302 patients with DM who presented to the ED with AECOPD. Patients were excluded because of incomplete data $(n=27)$, hypoglycemia $(n=11)$, and diabetic ketoacidosis or a hyperosmolar hyperglycemic state $(n=13)$. Incomplete data were mainly related to a lack of ordered HbA1c levels $(n=16)$. We enrolled 251 patients after the chart review. The demographic data and AECOPD-related clinical features of the enrolled patients are shown in Table 1.

Table I Characteristics of the enrolled patients

\begin{tabular}{|c|c|}
\hline Characteristic & $\mathbf{N}=\mathbf{2 5}$ I \\
\hline Age (years) & $76.0 \pm 12.6$ \\
\hline Gender (male) & $211(84.1 \%)$ \\
\hline Corticosteroid use & 101 (40.2\%) \\
\hline Congestive heart failure & $44(17.5 \%)$ \\
\hline Coronary artery disease & 85 (33.9\%) \\
\hline High-risk group & 179 (7I.3\%) \\
\hline Malignancy & 32 (I2.7\%) \\
\hline Cerebrovascular accident & $39(15.5 \%)$ \\
\hline Pulmonary infection & $84(33.5 \%)$ \\
\hline Chronic kidney disease & $60(23.9 \%)$ \\
\hline Smoking & $214(85.3 \%)$ \\
\hline Blood glucose at admission, $\mathrm{mg} / \mathrm{dL}$ & $225.9 \pm 148.6$ \\
\hline Hemoglobin Alc, \% & $7.9 \pm 2.1$ \\
\hline Glycemic gap, mg/dL & $45.9 \pm 123.3$ \\
\hline Stress hyperglycemic ratio & $1.3 \pm 1.4$ \\
\hline Modified stress hyperglycemia ratio & $277.2 \pm 14.1$ \\
\hline Acute respiratory failure & $35(13.9 \%)$ \\
\hline Hospital stay (days) & $9.4 \pm 13.1$ \\
\hline
\end{tabular}

Note: Data presented as mean \pm SD or $\mathrm{n}(\%)$.
As expected, compared with the patients in the high-risk COPD group, the patients in the low-risk COPD group had significantly lower glycemic gaps and modified stress hyperglycemia ratios, indicating a lower degree of $\mathrm{SIH}$, but did not have lower stress hyperglycemia ratios (Table 2). Compared with patients who did not present with ARF, patients with ARF had a significantly higher prevalence of corticosteroid use, exhibited concurrent pulmonary infections, and had higher glycemic gaps, higher stress hyperglycemia ratios, and longer hospital stays (Table 3).

\section{Association among acute hyperglycemia, HbAlc-based adjusted glycemic variables, and AECOPD}

The associations among the glycemic gap, stress hyperglycemia ratio, modified stress hyperglycemia ratio, and COPD classification are shown in Figure 1. These three HbAlcbased adjusted glycemic variables were significantly and positively correlated with the COPD severity classification. As shown in Table 4, a multivariable regression analysis revealed that pulmonary infection was the major determinant for the development of ARF. HbA1c-based adjusted glycemic variables were not independent risk factors for the development of ARF. Compared with the blood glucose level at admission (0.550, 95\% CI: $0.486-0.612)$, the glycemic gap, stress hyperglycemia ratio, and modified stress

Table 2 Comparison of patients who were admitted to the ED with AECOPD in the low- or high-risk groups

\begin{tabular}{|c|c|c|c|}
\hline Variable & $\begin{array}{l}\text { High-risk } \\
(n=I 79)\end{array}$ & $\begin{array}{l}\text { Low-risk } \\
(n=72)\end{array}$ & P-value \\
\hline Age (years) & $75.9 \pm 12.4$ & $76.2 \pm 13.1$ & 0.87 \\
\hline Gender (male) & 155 (86.6\%) & $56(77.8 \%)$ & 0.08 \\
\hline Chronic steroid use & $89(49.7 \%)$ & $12(16.7 \%)$ & $<0.0 I^{*}$ \\
\hline Congestive heart failure & 31 (I7.3\%) & $13(11.1 \%)$ & 0.89 \\
\hline Coronary artery disease & $58(32.4 \%)$ & $27(37.5 \%)$ & 0.44 \\
\hline Cerebrovascular accident & $27(15.1 \%)$ & $12(16.7 \%)$ & 0.75 \\
\hline Malignancy & $21(11.7 \%)$ & II (I5.3\%) & 0.45 \\
\hline Pulmonary infection & $58(32.6 \%)$ & $26(36.1 \%)$ & 0.59 \\
\hline Chronic kidney disease & $45(25.1 \%)$ & I5 (20.8\%) & 0.47 \\
\hline Smoking & $160(89.4 \%)$ & $54(75.0 \%)$ & $<0.01 *$ \\
\hline $\begin{array}{l}\text { Blood glucose at } \\
\text { admission, mg/dL }\end{array}$ & $244.0 \pm 160.3$ & $181.0 \pm 102.2$ & $<0.0 I^{*}$ \\
\hline Hemoglobin Alc, \% & $8.1 \pm 2.0$ & $7.5 \pm 2.1$ & $0.03^{*}$ \\
\hline Glycemic gap, mg/dL & $58.8 \pm 133.0$ & $13.7 \pm 87.6$ & $<0.01 *$ \\
\hline Stress hyperglycemia ratio & $1.4 \pm 1.6$ & $\mathrm{I} . \mathrm{I} \pm 0.5$ & 0.11 \\
\hline $\begin{array}{l}\text { Modified stress } \\
\text { hyperglycemia ratio }\end{array}$ & $29.2 \pm 14.8$ & $24.1 \pm I 1.5$ & $<0.0 I^{*}$ \\
\hline Acute respiratory failure & $31(17.3 \%)$ & $4(5.6 \%)$ & $0.02 *$ \\
\hline Hospital stay (days) & $9.8 \pm 10.0$ & $8.4 \pm 18.8$ & 0.42 \\
\hline
\end{tabular}

Notes: Data presented as mean \pm SD or $n(\%) . * P<0.05$.

Abbreviations: $A E C O P D$, acute exacerbation of chronic obstructive pulmonary disease; ED, emergency department. 
Table 3 Comparison of patients who were admitted to the ED with AECOPD with or without ARF

\begin{tabular}{|c|c|c|c|}
\hline Variable & $\operatorname{ARF}(n=35)$ & No ARF $(n=2 \mid 6)$ & $P$-value \\
\hline Age (years) & $77.5 \pm 11.6$ & $75.8 \pm 12.8$ & 0.46 \\
\hline Gender (male) & $29(82.9 \%)$ & $182(84.3 \%)$ & 0.83 \\
\hline Corticosteroid use & $19(54.3 \%)$ & $82(38.0 \%)$ & 0.07 \\
\hline Congestive heart failure & 8 (22.9\%) & $36(16.7 \%)$ & 0.37 \\
\hline Coronary artery disease & I5 (42.9\%) & $70(32.4 \%)$ & 0.23 \\
\hline Malignancy & $3(8.6 \%)$ & $29(13.4 \%)$ & 0.42 \\
\hline Cerebrovascular accident & $4(\mathrm{I} 1.4 \%)$ & $35(16.2 \%)$ & 0.47 \\
\hline Pulmonary infection & $18(5 \mid .4 \%)$ & $66(30.7 \%)$ & $0.02 *$ \\
\hline Chronic kidney disease & $6(17.1 \%)$ & $54(25.0 \%)$ & 0.31 \\
\hline Smoking & 32 (9I.4\%) & $182(84.3 \%)$ & 0.27 \\
\hline $\begin{array}{l}\text { Blood glucose at } \\
\text { admission, } \mathrm{mg} / \mathrm{dL}\end{array}$ & $246.9 \pm 179.6$ & $222.6 \pm 143.2$ & 0.37 \\
\hline Hemoglobin Alc, \% & $7.3 \pm 1.3$ & $8.0 \pm 2.1$ & 0.06 \\
\hline Glycemic gap, mg/dL & $84.3 \pm 115.7$ & $39.7 \pm 115.7$ & $0.05^{*}$ \\
\hline Stress hyperglycemia ratio & $1.5 \pm 0.8$ & $1.3 \pm 1.4$ & 0.22 \\
\hline $\begin{array}{l}\text { Modified stress } \\
\text { hyperglycemia ratio }\end{array}$ & $32.8 \pm 17.7$ & $26.9 \pm 13.3$ & $0.02 *$ \\
\hline Hospital stay (days) & $18.3 \pm 17.0$ & $8.0 \pm 11.8$ & $<0.01 *$ \\
\hline
\end{tabular}

Notes: Data presented as mean $\pm S D$ or $n(\%)$. $* P<0.05$.

Abbreviations: AECOPD, acute exacerbation of chronic obstructive pulmonary disease; ARF, acute respiratory failure; $E D$, emergency department.

hyperglycemia ratio had greater AUROC values (AUROC: 0.612, 95\% CI: 0.548-0.672, $P=0.02$; AUROC: $0.61095 \%$ CI: $0.550-0.673, P=0.01$; and AUROC: $0.612,95 \% \mathrm{CI}$ : $0.549-0.673, P=0.01$, respectively) for the development of $\mathrm{ARF}$ in the pairwise comparison (Figure 2).

\section{Association between corticosteroid use and chronic blood glucose control}

As shown in Table 5, corticosteroid use was not associated with significant changes in blood glucose control (corticosteroid users vs non-corticosteroid users: $7.8 \% \pm 1.7 \%$ vs $7.9 \pm 2.3$, $P=0.843$ ). To further decipher the association among blood glucose, corticosteroid use, and ARF development, we reclassified the patients and found that the HbAlc-based glycemic variables were significantly different in patients with and without ARF who were also corticosteroid users, whereas these variables were not significantly different in patients with and without ARF who were not corticosteroid users (Figure 3).

As shown in Table 6, corticosteroid users were significantly more prevalent in the high-risk COPD group, showed a greater likelihood of developing coronary artery disease, and were more likely to smoke than non-corticosteroid users. However, significant differences were not observed in $\mathrm{HbAlc}$ levels, acute hyperglycemia, and HbA1c-based adjusted glycemic variables between these two groups. As shown in Table 7, there were statistically significant differences regarding glycemic gaps and stress hyperglycemia ratios related to the association between $\mathrm{HbAlc}$-based adjusted glycemic variables and chronic blood glucose control.

\section{Discussion}

The major findings of the present study are as follows: 1) pulmonary infection is the major risk factor for AECOPD; 2) a higher glycemic gap and modified stress hyperglycemia ratio were associated with the development of ARF in patients with DM admitted to the ED because of AECOPD; 3) the glycemic gap and modified stress hyperglycemia ratio had superior discriminative power relative to that of acute hyperglycemia and $\mathrm{HbA} 1 \mathrm{c}$ for predicting the development of ARF, although the HbA1c-adjusted glycemic variables alone were not independent risk factors for ARF; and 4) corticosteroid use did not significantly increase $\mathrm{HbA} 1 \mathrm{c}$ levels, the values of HbAlc-derived variables, or the development of acute hyperglycemia.

DM is a risk factor for AECOPD. ${ }^{18}$ Patients with DM and AECOPD frequently (50\%-80\% of patients) presented with hyperglycemia during their hospital stay and experienced longer hospital stays and higher mortality rates than patients without DM. ${ }^{19,20}$ Hyperglycemia could have adverse effects on the lungs because it can promote the glycosylation of connective tissues, a decline in pulmonary elastic recoil,


Figure I Glycemic gaps, stress hyperglycemia ratios, modified stress hyperglycemia ratios, and COPD classifications. Abbreviation: COPD, chronic obstructive pulmonary disease. 
Table 4 Univariable and multivariable regression analyses for developing ARF

\begin{tabular}{|c|c|c|c|c|c|}
\hline \multirow[t]{3}{*}{ Variable } & \multicolumn{2}{|l|}{ Univariable } & \multicolumn{3}{|l|}{ Multivariable } \\
\hline & \multirow[t]{2}{*}{ HR (95\% CI) } & \multirow[t]{2}{*}{$P$-value } & \multicolumn{3}{|l|}{ Model I } \\
\hline & & & Variable & HR (95\% Cl) & $P$-value \\
\hline Age & $1.011(0.981-1.042)$ & 0.46 & Age & $1.013(0.980-1.046)$ & 0.45 \\
\hline Gender (male) & $1.108(0.427-2.870)$ & 0.83 & Gender (male) & $1.032(0.37 \mathrm{I}-2.872)$ & 0.95 \\
\hline Corticosteroid use & $1.941(0.945-3.985)$ & 0.07 & High-risk group & $2.918(0.935-9.106)$ & 0.07 \\
\hline Congestive heart failure & I.48I (0.623-3.523) & 0.37 & Pulmonary infection & $2.482(1.164-5.295)$ & $0.02 *$ \\
\hline Coronary artery disease & $1.564(0.756-3.238)$ & 0.23 & Glycemic gap & $1.002(0.999-1.005)$ & 0.12 \\
\hline High-risk group & $3.561(1.209-10.487)$ & $0.02 *$ & & & \\
\hline Malignancy & $0.605(0.174-2.102)$ & 0.42 & & & \\
\hline Cerebrovascular accident & $0.667(0.222-2.009)$ & 0.47 & & & \\
\hline Pulmonary infection & $2.390(1.160-4.928)$ & $0.02 *$ & & & \\
\hline Chronic kidney disease & $0.621(0.245-1.575)$ & 0.31 & Model 2 & & \\
\hline Smoking & $1.993(0.577-6.878)$ & 0.27 & Variable & HR (95\% CI) & $P$-value \\
\hline Blood glucose at admission & $1.001(0.999-1.003)$ & 0.37 & Age & $1.012(0.980-1.046)$ & 0.46 \\
\hline Hemoglobin Alc, \% & $0.81 \mathrm{I}(0.650-1.00 \mathrm{I})$ & 0.06 & Gender (male) & $1.013(0.363-2.824)$ & 0.98 \\
\hline Glycemic gap & $1.003(1.000-1.005)$ & $0.05 *$ & High-risk group & $2.910(0.933-9.075)$ & 0.07 \\
\hline Stress hyperglycemia ratio & $1.078(0.886-1.311)$ & 0.45 & Pulmonary infection & $2.507(1.175-5.348)$ & $0.02 *$ \\
\hline Modified stress & $1.026(1.003-1.050)$ & $0.03 *$ & Modified stress & $1.023(0.999-1.048)$ & 0.06 \\
\hline hyperglycemia ratio & & & hyperglycemia ratio & & \\
\hline
\end{tabular}

Notes: $* P<0.05$. Multivariable analysis included all variables with $P$-values $<0.05$ from the univariable analysis, age and gender. Model I: incorporating glycemic gap; model 2 : incorporating modified stress hyperglycemia ratio into multivariable analysis.

Abbreviations: ARF, acute respiratory failure; $\mathrm{Cl}$, confidence interval; $\mathrm{HR}$, hazard ratio.

weakness, and/or inflammation in respiratory muscles, and a susceptibility to bacterial infection. ${ }^{21-24}$ SIH could be attributed to the presence of excess levels of counter-regulatory hormones and inflammatory cytokines and to increases in gluconeogenesis and hepatic insulin resistance. ${ }^{6,7,25}$ Because the severity of SIH is positively correlated with disease severity, SIH could be used to predict the outcomes of critically ill patients. Acute fluctuations in blood glucose levels generally reflect disease severity; however, blood glucose levels measured during acute events could reflect either chronic blood glucose control, acute fluctuations in blood glucose, or both in patients with DM. In investigations of the association between SIH and adverse outcomes in AECOPD patients, the complex and confounding effects of corticosteroid use should also be further considered. Therefore, SIH itself should be clarified and redefined, specifically in patients with DM. HbA1c levels are characterized by lower biological variability, and they are relatively unaffected by acute stress. Thus, the possible influence of long-term glycemic control on disease severity or outcome could be controlled by using HbAlc-based adjustments. A history of DM but not hyperglycemia impacts the long-term mortality associated with AECOPD. ${ }^{26}$ Our previous work showed an association between elevated glycemic gaps and adverse outcomes in patients with DM presenting with liver abscesses, communityacquired pneumonia, and acute myocardial infarction, as well as the outcomes of critically ill patients who were admitted to intensive care units (ICUs). ${ }^{11-14}$ Consistent with

\begin{tabular}{|l|l|l|}
\hline & AUC & $\mathbf{9 5 \%} \mathbf{C l}$ \\
\hline Glycemic gap & 0.612 & $0.548-0.672$ \\
\hline Modified stress hyperglycemia ratio & 0.612 & $0.549-0.673$ \\
\hline Stress hyperglycemia ratio & 0.610 & $0.550-0.673$ \\
\hline HbA1c & 0.575 & $0.511-0.637$ \\
\hline Blood glucose at admission & 0.562 & $0.498-0.624$ \\
\hline
\end{tabular}

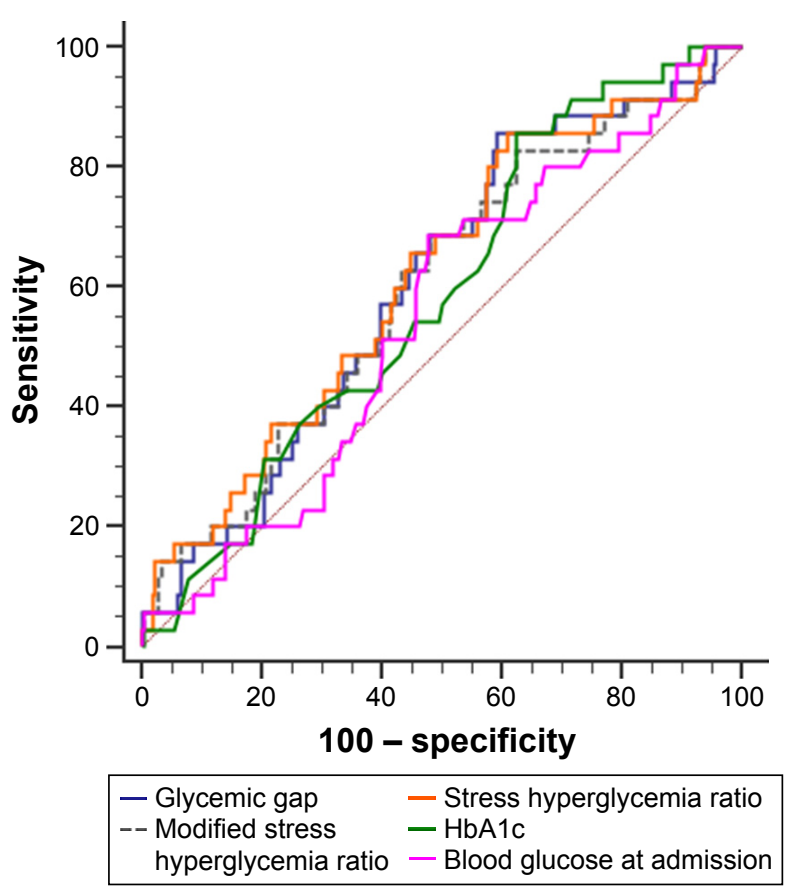

Figure 2 ROC of acute hyperglycemia, HbAlc level, glycemic gap, stress hyperglycemia ratio, modified stress hyperglycemia ratio, and acute respiratory failure development in patients presenting to the ED with AECOPD.

Abbreviations: AECOPD, acute exacerbation of chronic obstructive pulmonary disease; AUC, area under the curve; $\mathrm{Cl}$, confidence interval; $\mathrm{ED}$, emergency department; HbAlc, hemoglobin Alc; ROC, receiver-operator characteristic. 
Table 5 Comparison of the characteristics of patients with AECOPD during chronic corticosteroid use with or without the development of ARF

\begin{tabular}{|c|c|c|c|c|c|c|}
\hline \multirow[t]{2}{*}{ Variable } & \multicolumn{3}{|c|}{ Corticosteroid users } & \multicolumn{3}{|c|}{ Non-corticosteroid users } \\
\hline & $\operatorname{ARF}(n=19)$ & No ARF (n=82) & $P$-value & $\operatorname{ARF}(n=16)$ & No ARF $(n=134)$ & $P$-value \\
\hline Age (years) & $76.7 \pm 12.5$ & $75.2 \pm 12.4$ & 0.62 & $78.3 \pm 10.7$ & $76.1 \pm 13.0$ & 0.52 \\
\hline Gender (male) & $14(73.7 \%)$ & $7 \mathrm{l}(86.6 \%)$ & 0.17 & $15(93.8 \%)$ & III (88.1\%) & 0.26 \\
\hline Congestive heart failure & $4(21.1 \%)$ & $18(22.0 \%)$ & 0.93 & $4(25.0 \%)$ & $18(13.4 \%)$ & 0.22 \\
\hline Coronary artery disease & $6(31.6 \%)$ & $2 \mathrm{I}(25.6 \%)$ & 0.60 & $9(56.3 \%)$ & 49 (36.6\%) & 0.13 \\
\hline High-risk group & $19(100 \%)$ & 70 (78.7\%) & 0.08 & $12(75.0 \%)$ & 78 (58.2\%) & 0.20 \\
\hline Malignancy & $2(10.5 \%)$ & $12(14.6 \%)$ & 0.64 & I (6.3\%) & $17(12.7 \%)$ & 0.45 \\
\hline Cerebrovascular accident & $2(10.5 \%)$ & $9(11.0 \%)$ & 0.96 & $2(12.5 \%)$ & $26(19.4 \%)$ & 0.50 \\
\hline Pulmonary infection & $8(42.1 \%)$ & $21(25.6 \%)$ & 0.15 & $10(62.5 \%)$ & $45(33.8 \%)$ & $0.03^{*}$ \\
\hline Chronic kidney disease & $2(20.5 \%)$ & $24(29.3 \%)$ & 0.09 & $4(25.0 \%)$ & $20(22.4 \%)$ & 0.81 \\
\hline Smoking & $18(94.7 \%)$ & $74(90.2 \%)$ & 0.56 & $14(87.5 \%)$ & $108(80.6 \%)$ & 0.50 \\
\hline Blood glucose at admission, $\mathrm{mg} / \mathrm{dL}$ & $203.9 \pm 87.5$ & $242.6 \pm 142.1$ & 0.49 & $298.0 \pm 242.4$ & $219.4 \pm 144.3$ & 0.22 \\
\hline Hemoglobin Alc, \% & $7.1 \pm 1.1$ & $8.1 \pm 1.8$ & $0.02 *$ & $7.6 \pm 1.6$ & $8.0 \pm 2.4$ & 0.49 \\
\hline Glycemic gap, mg/dL & $47.4 \pm 97.4$ & $42.1 \pm 121.9$ & 0.86 & $128.0 \pm 205.7$ & $38.2 \pm|2| .1$ & $0.01 *$ \\
\hline Stress hyperglycemia ratio & $1.4 \pm 0.7$ & $1.2 \pm 0.6$ & 0.30 & $1.6 \pm 0.85$ & $1.3 \pm 0.8$ & 0.52 \\
\hline Modified stress hyperglycemia ratio & $29.6 \pm 14.1$ & $27.4 \pm 13.8$ & 0.53 & $36.5 \pm 21.0$ & $26.6 \pm 13.1$ & $0.01 *$ \\
\hline Hospital stay (days) & $19.7 \pm 11.9$ & $8.7 \pm 17.5$ & $0.02 *$ & $17.9 \pm 22.0$ & $7.5 \pm 6.3$ & $<0.0 \mathrm{I}^{*}$ \\
\hline
\end{tabular}

Notes: Data presented as mean \pm SD or $n(\%) . * P<0.05$.

Abbreviations: AECOPD, acute exacerbation of chronic obstructive pulmonary disease; ARF, acute respiratory failure.

these results, we again found that elevated glycemic gaps and modified stress hyperglycemia ratios were associated with the development of ARF in patients with DM during AECOPD. Although the discriminative power of the glycemic gap and stress hyperglycemia ratio for predicting the development of ARF in AECOPD patients was limited, we propose that $\mathrm{HbA} 1 \mathrm{c}$-adjusted glycemic variables rather than acute hyperglycemia and $\mathrm{HbA} 1 \mathrm{c}$ levels alone should be used as an indicator of disease severity in patients with DM.

A multivariable regression analysis showed that pulmonary infection rather than $\mathrm{HbAlc}$-based adjusted glycemic variables was the major determinant for the development
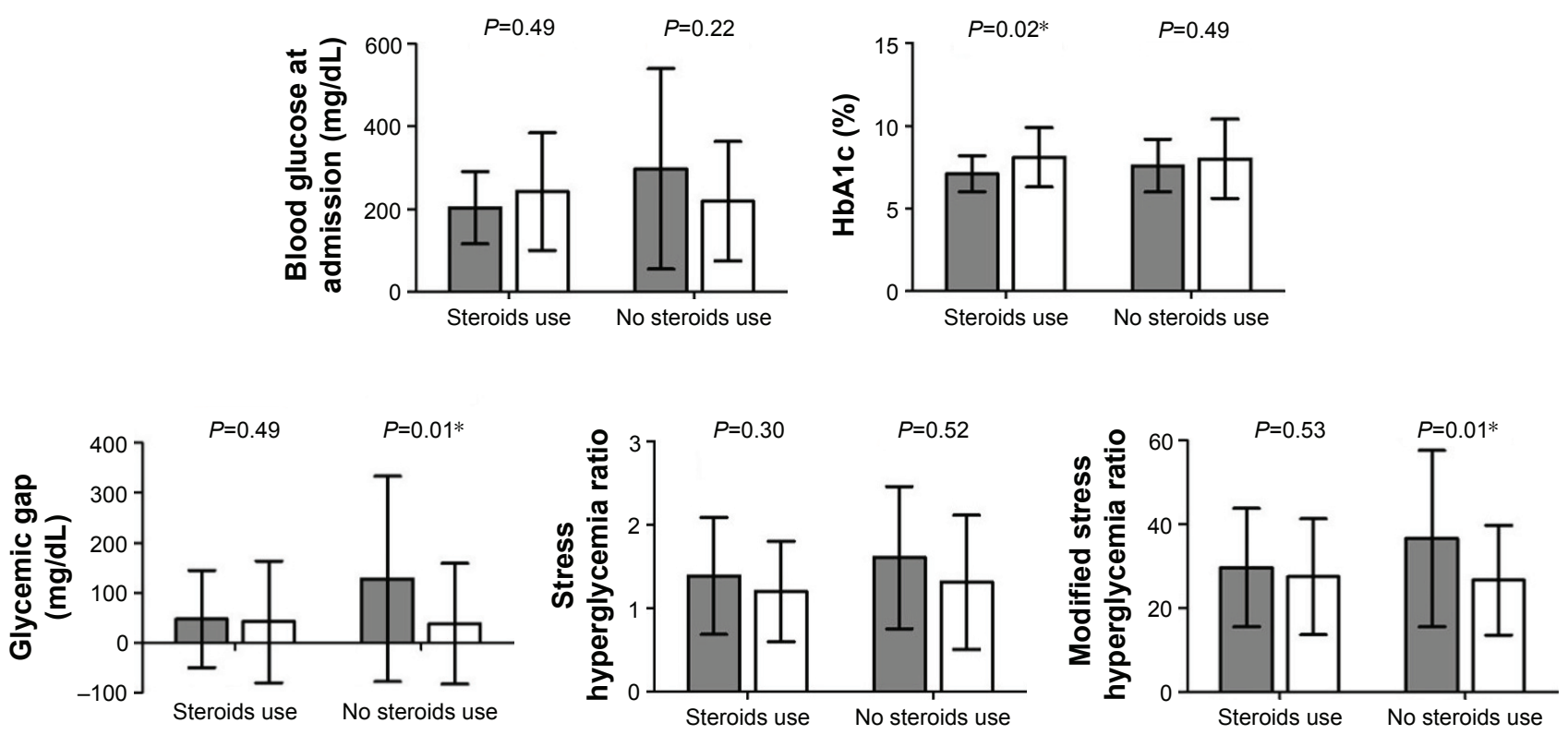

$\square$ Acute respiratory failure $\square$ No acute respiratory failure

Figure 3 Effects of corticosteroid use on acute hyperglycemia, HbAlc levels, glycemic gaps, stress hyperglycemia ratios, and modified stress hyperglycemia ratios in patients who were admitted to the ED with AECOPD.

Note: $* P<0.05$.

Abbreviations: AECOPD, acute exacerbation of chronic obstructive pulmonary disease; ED, emergency department; HbAIc, hemoglobin Alc. 
Table 6 Comparison of the characteristics of corticosteroid users versus non-corticosteroid users among AECOPD patients

\begin{tabular}{|c|c|c|c|}
\hline Variable & $\begin{array}{l}\text { Corticosteroid } \\
\text { users, }(n=101)\end{array}$ & $\begin{array}{l}\text { Non-corticosteroid } \\
\text { users, }(n=150)\end{array}$ & $P$-value \\
\hline Age (years) & $75.5 \pm 12.3$ & $76.3 \pm 12.8$ & 0.95 \\
\hline Gender (male) & 85 (84.2\%) & $126(84.0 \%)$ & 0.97 \\
\hline $\begin{array}{l}\text { Congestive } \\
\text { heart failure }\end{array}$ & $22(21.8 \%)$ & $22(14.7 \%)$ & 0.15 \\
\hline $\begin{array}{l}\text { Coronary } \\
\text { artery disease }\end{array}$ & 27 (26.7\%) & $58(38.7 \%)$ & $0.05 *$ \\
\hline High-risk group & $89(88.1 \%)$ & $90(60.0 \%)$ & $<0.0 I^{*}$ \\
\hline Malignancy & 14 (I3.9\%) & 17 (12.7\%) & 0.67 \\
\hline $\begin{array}{l}\text { Cerebrovascular } \\
\text { accident }\end{array}$ & II (I0.9\%) & $28(18.7 \%)$ & 0.10 \\
\hline Pulmonary infection & $29(28.7 \%)$ & $76.3 \pm 12.8$ & 0.19 \\
\hline $\begin{array}{l}\text { Chronic } \\
\text { kidney disease }\end{array}$ & $26(25.7 \%)$ & $34(22.7 \%)$ & 0.58 \\
\hline Smoking & 92 (9l.1\%) & $122(81.3 \%)$ & $0.03 *$ \\
\hline $\begin{array}{l}\text { Blood glucose at } \\
\text { admission, } \mathrm{mg} / \mathrm{dL}\end{array}$ & $223.2 \pm 113.5$ & $227.8 \pm 158.4$ & 0.81 \\
\hline Hemoglobin Alc, \% & $7.9 \pm 1.7$ & $7.9 \pm 2.3$ & 0.84 \\
\hline Glycemic gap, mg/dL & $43.1 \pm 117.3$ & $47.8 \pm 127.5$ & 0.77 \\
\hline $\begin{array}{l}\text { Stress } \\
\text { hyperglycemia ratio }\end{array}$ & $1.2 \pm 0.6$ & $1.3 \pm 1.7$ & 0.49 \\
\hline $\begin{array}{l}\text { Modified stress } \\
\text { hyperglycemia ratio }\end{array}$ & $27.6 \pm 13.8$ & $27.6 \pm 14.4$ & 0.91 \\
\hline $\begin{array}{l}\text { Acute } \\
\text { respiratory failure }\end{array}$ & 19 (I8.8\%) & $16(10.7 \%)$ & 0.19 \\
\hline Hospital stay (days) & $10.5 \pm 17.0$ & $8.6 \pm 9.7$ & 0.26 \\
\hline Mortality & $2(2.0 \%)$ & $4(2.7 \%)$ & 0.73 \\
\hline
\end{tabular}

Notes: Data presented as mean \pm SD or $\mathrm{n}(\%)$. $* \mathrm{P}<0.05$.

Abbreviations: AECOPD, acute exacerbation of chronic obstructive pulmonary disease.

of ARF in DM patients during AECOPD. Our results also showed that those $\mathrm{HbA} 1 \mathrm{c}-$ based adjusted glycemic variables could reflect the occurrence of an ARF. However, those HbA1c-based adjusted glycemic variables are not independent risk factors for developing ARF in patients with DM during AECOPD, whereas pulmonary infection is an independent risk factor. A previous study reported that the susceptibility to bacterial infection could represent a lifethreatening complication associated with hyperglycemia in COPD patients with $\mathrm{DM},{ }^{27}$ and this result is consistent

Table 7 The association between HbAlc-based adjusted glycemic variables and chronic blood glucose control

\begin{tabular}{|c|c|c|c|c|}
\hline Variable & $\begin{array}{l}\text { HbAlc } \\
<7 \%, \\
(n=100)\end{array}$ & $\begin{array}{l}\mathbf{7} \% \leq \text { HbAlc } \\
<9 \% \\
(n=92)\end{array}$ & $\begin{array}{l}\text { HbAlc } \\
\geq 9 \%, \\
(n=59)\end{array}$ & $P$-value \\
\hline Glycemic gap & $23.8 \pm 76.7$ & $35.6 \pm 101.0$ & $99.3 \pm 188.5$ & $<0.01^{*}$ \\
\hline $\begin{array}{l}\text { Stress } \\
\text { hyperglycemia ratio }\end{array}$ & $1.2 \pm 0.6$ & $1.2 \pm 0.6$ & $1.4 \pm 0.7$ & 0.10 \\
\hline $\begin{array}{l}\text { Modified stress } \\
\text { hyperglycemia ratio }\end{array}$ & $24.6 \pm 12.2$ & $27.5 \pm 12.8$ & $33.4 \pm 17.2$ & $<0.01 *$ \\
\hline
\end{tabular}

Notes: Data presented as mean \pm SD. $* P<0.05$.

Abbreviation: $\mathrm{HbAlc}$, hemoglobin Alc. with our finding that pulmonary infection is a cardinal risk factor for the development of ARF. Indeed, our previous study showed that patients with an elevated glycemic gap had an odds ratio of 3.84 for the incidence of combined adverse outcomes. The incorporation of the glycemic gap into existing pneumonia severity scores could increase the discriminative performance for predicting the development of adverse outcomes. ${ }^{11}$

Inhaled or systemic corticosteroid therapy is a factor that potentially affects the glycemic profile. Systemic corticosteroid therapy is frequently applied to patients in high-risk COPD groups or during AECOPD to shorten the recovery time, improve pulmonary function and oxygenation, reduce the risk of early relapse and treatment failure, and decrease the length of the hospital stay. ${ }^{16,28}$ However, whether corticosteroid therapy is associated with hyperglycemia in patients with DM during AECOPD remains controversial. Although studies have indicated that corticosteroid therapy increases the risk of hyperglycemia in all individuals with an underlying respiratory disease, ${ }^{29,30}$ other studies have argued that corticosteroid treatment does not have a significant effect on the HbAlc levels in patients with DM and AECOPD. ${ }^{31,32}$ As expected, we also found that patients in the high-risk COPD group had a higher rate of developing ARF and were more likely to use corticosteroids. ${ }^{33}$ However, the use of corticosteroids should not significantly elevate the blood glucose levels in patients with DM. Another noteworthy finding is that corticosteroid users had a higher rate of coronary artery disease. One study indicated that treatment with high-dose glucocorticoids (daily dose $>7.5 \mathrm{mg}$ of prednisolone equivalent) appeared to be associated with an increased risk for cardiovascular disease. The adverse effects of corticosteroids on cardiovascular risk factors might be related to their effects on blood pressure, blood glucose levels, and lipid profile control and comorbidities. ${ }^{34}$

When estimating SIH, we suggest that chronic blood glucose control and any other factor that might influence physiological stress, such as corticosteroid use, should be considered in addition to absolute blood glucose levels. We further analyzed the associations among blood glucose levels, corticosteroid use, and ARF development. Corticosteroid-using patients who developed ARF had significantly lower $\mathrm{HbA} 1 \mathrm{c}$ levels and longer hospital stays than non-corticosteroid-using patients, whereas non-corticosteroidusing patients who developed ARF had significantly higher glycemic gaps and modified stress hyperglycemia ratios, higher risks of pulmonary infection, and longer hospital stays than corticosteroid-using patients. It is worth noting that in 
corticosteroid users, these HbA1c-based adjusted glycemic variables were not significantly different between patients with and without ARF. In addition, lower HbA1c levels were observed in patients with ARF and patients in the high-risk group. Although these findings might seem counterintuitive, they were consistent with the proposed "diabetes paradox," in which glycemic control is not independently associated with illness severity in critically ill patients with DM. ${ }^{35,36}$ Previous studies have shown that in patients with high $(>9 \%)$ levels of HbA1c, there was an inverse relationship between glycemic control and mortality - higher blood glucose levels during ICU stays were associated with lower mortality even after adjusting for possible confounding factors. ${ }^{36,37}$ Although patients who were classified as being at high risk had significantly higher HbA1c levels, glycemic gaps, and modified stress hyperglycemia ratios, patients who developed ARF showed a trend toward lower HbA1c levels but still had significantly higher glycemic gaps and modified stress hyperglycemia ratios. The possible adverse consequences regarding more stringent glycemic control in patients with DM have been further illustrated in the Action in Diabetes and Vascular Diseases: Preterax and Diamicron Modified Release Controlled Evaluation (ADVANCE) and Action to Control Cardiovascular Risk in Diabetes (ACCORD) studies. ${ }^{38,39}$ Several hypothetical reasons have been proposed to explain the lack of an association between HbA1c levels and patient outcomes, including physiological and cellular readjustments in response to hyperglycemia and the potential effects of hypoglycemia. ${ }^{40}$ Hypoglycemia increases platelet aggregation and fibrinogen formation, which may accelerate vascular damage in the lung and thereby result in a higher risk for in-hospital complications and longer hospitalizations. ${ }^{41-43}$ In addition to chronic blood glucose control, hypoglycemia and glycemic variability are also independent factors for mortality in critically ill patients. ${ }^{36}$ A previous study also revealed that $\mathrm{HbA} 1 \mathrm{c}$ levels lower than $6.0 \%$ and higher than $10 \%$ were associated with an increased risk of COPD in patients with type 2 DM. ${ }^{32}$ Systemic corticosteroid administration may suppress inflammation, alleviate endogenous stress, and hinder subsequent SIH. These effects may explain why glycemic gaps and stress hyperglycemia ratios were not significantly different among the corticosteroid users and indicated diminished physiological stress because of AECOPD. Another relevant issue is that elevated blood $\mathrm{HbA1c}$ levels lead to an overestimation of $\mathrm{SaO}_{2}$ based on $\mathrm{SpO}_{2}$, suggesting that arterial blood gas analysis may be needed for assessing type 2 DM patients with poor glycemic control during the treatment of hypoxemia. ${ }^{44}$

\section{Limitations}

Our study has several limitations. First, it was a retrospective study; therefore, it may have been subject to selection bias. Second, the adequacy of acute glycemic control during hospitalization might have influenced the outcomes. We did not specifically address treatments regarding DM management and corticosteroid dosage, which might have impacted glycemic control and disease progression. A recent metaanalysis showed no mortality benefit of tight glycemic control in critically ill patients, although a fivefold greater incidence of hypoglycemia was observed compared with the effects of mild or very mild control. ${ }^{45}$ We could not elucidate the association between the $\mathrm{HbA} 1 \mathrm{c}$-adjusted hyperglycemic variables and hyperinsulinemia because serum insulin levels were not routinely determined in AECOPD patients. We believe that a prospective study that incorporates DM management, corticosteroid dosage, serum insulin levels, insulin resistance, and adrenocorticotropic hormone data in conjunction with measurements of glycemic gaps and stress hyperglycemia ratios in patients with or without diabetes should be conducted to clarify the interactions between corticosteroid use, $\mathrm{HbAlc}$, and SIH and to justify the usefulness of HbAlc-based adjusted glycemic variables as biomarkers.

\section{Conclusion}

Higher HbA1c-based adjusted glycemic variables were associated with a high risk of COPD and the development of ARF in patients presenting to an ED with AECOPD. We conclude that both the glycemic gap and modified stress hyperglycemia ratio could be used to assess illness severity in patients presenting with AECOPD.

\section{Acknowledgments}

This study was supported by a grant from the Tri-Service General Hospital, National Defense Medical Center, Taipei, Taiwan (TSGH-C106-048) and Ministry of Science and Technology, Taiwan (MOST-104-2314-B-106-043-MY2).

\section{Author contributions}

CJY had full access to all data in the study and takes responsibility for the integrity of the data and the accuracy of the data analysis. CHL, SET, CWH, and SHT contributed to the study design; JCW and SHT contributed to the literature review and writing of the manuscript; WCC and ZCT contributed to the data collection; CJY contributed to the statistical analysis. All authors contributed toward data analysis, drafting and critically revising the paper, gave final approval of the version to be published, and agree to be accountable for all aspects of the work. 


\section{Disclosure}

The authors report no conflicts of interest in this work.

\section{References}

1. Caughey GE, Roughead EE, Vitry AI, McDermott RA, Shakib S, Gilbert AL. Comorbidity in the elderly with diabetes: Identification of areas of potential treatment conflicts. Diabetes Res Clin Pract. 2010; 87(3):385-393.

2. Kerr EA, Heisler M, Krein SL, et al. Beyond comorbidity counts: how do comorbidity type and severity influence diabetes patients' treatment priorities and self-management? J Gen Intern Med. 2007;22(12): $1635-1640$.

3. Edriss H, Selvan K, Sigler M, Nugent K. Glucose levels in patients with acute respiratory failure requiring mechanical ventilation. $J$ Intensive Care Med. Epub 2016 Feb 28.

4. Flattet Y, Garin N, Serratrice J, Perrier A, Stirnemann J, Carballo S. Determining prognosis in acute exacerbation of COPD. Int J Chron Obstruct Pulmon Disease. 2017;12:467-475.

5. Baker EH, Janaway CH, Philips BJ, et al. Hyperglycaemia is associated with poor outcomes in patients admitted to hospital with acute exacerbations of chronic obstructive pulmonary disease. Thorax. 2006;61(4): 284-289.

6. Marik PE, Raghavan M. Stress-hyperglycemia, insulin and immunomodulation in sepsis. Intensive Care Med. 2004;30(5):748-756.

7. McCowen KC, Malhotra A, Bistrian BR. Stress-induced hyperglycemia. Crit Care Clin. 2001;17(1):107-124.

8. Kavanagh BP, McCowen KC. Clinical practice. Glycemic control in the ICU. N Engl J Med. 2010;363(26):2540-2546.

9. Oltmanns KM, Gehring H, Rudolf S, et al. Hypoxia causes glucose intolerance in humans. Am J Respir Crit Care Med. 2004;169(11): 1231-1237.

10. Glaser S, Kruger S, Merkel M, Bramlage P, Herth FJ. Chronic obstructive pulmonary disease and diabetes mellitus: a systematic review of the literature. Respiration. 2015;89(3):253-264.

11. Chen PC, Liao WI, Wang YC, et al. An elevated glycemic gap is associated with adverse outcomes in diabetic patients with community-acquired pneumonia. Medicine (Baltimore). 2015;94(34): e1456.

12. Liao WI, Lin CS, Lee CH, et al. An elevated glycemic gap is associated with adverse outcomes in diabetic patients with acute myocardial infarction. Sci Rep. 2016;6:27770.

13. Liao WI, Sheu WH, Chang WC, Hsu CW, Chen YL, Tsai SH. An elevated gap between admission and A1C-derived average glucose levels is associated with adverse outcomes in diabetic patients with pyogenic liver abscess. PLoS One. 2013;8(5):e64476.

14. Liao WI, Wang JC, Chang WC, Hsu CW, Chu CM, Tsai SH. Usefulness of glycemic gap to predict ICU mortality in critically Ill patients with diabetes. Medicine. 2015;94(36):e1525.

15. Roberts GW, Quinn SJ, Valentine N, et al. Relative hyperglycemia, a marker of critical illness: introducing the stress hyperglycemia ratio. J Clin Endocrinol Metab. 2015;100(12):4490-4497.

16. Vestbo J, Hurd SS, Agusti AG, et al. Global strategy for the diagnosis, management, and prevention of chronic obstructive pulmonary disease: GOLD executive summary. Am J Respir Crit Care Med. 2013; 187(4):347-365.

17. Nathan DM, Kuenen J, Borg R, Zheng H, Schoenfeld D, Heine RJ. Translating the $\mathrm{A} 1 \mathrm{C}$ assay into estimated average glucose values. Diabetes Care. 2008;31(8):1473-1478.

18. Santibanez M, Garrastazu R, Ruiz-Nunez M, et al. Predictors of hospitalized exacerbations and mortality in chronic obstructive pulmonary disease. PLoS One. 2016;11(6):e0158727.

19. Burt MG, Roberts GW, Aguilar-Loza NR, Quinn SJ, Frith PA, Stranks SN. Relationship between glycaemia and length of hospital stay during an acute exacerbation of chronic obstructive pulmonary disease. Intern Med J. 2013;43(6):721-724.
20. Parappil A, Depczynski B, Collett P, Marks GB. Effect of comorbid diabetes on length of stay and risk of death in patients admitted with acute exacerbations of COPD. Respirology. 2010;15(6):918-922.

21. Kinney GL, Black-Shinn JL, Wan ES, et al. Pulmonary function reduction in diabetes with and without chronic obstructive pulmonary disease. Diabetes Care. 2014;37(2):389-395.

22. Davis WA, Knuiman M, Kendall P, Grange V, Davis TM. Glycemic exposure is associated with reduced pulmonary function in type 2 diabetes: the Fremantle Diabetes Study. Diabetes Care. 2004;27(3):752-757.

23. Lim SY, Rhee EJ, Sung KC. Metabolic syndrome, insulin resistance and systemic inflammation as risk factors for reduced lung function in Korean nonsmoking males. J Korean Med Sci. 2010;25(10):1480-1486.

24. Lawlor DA, Ebrahim S, Smith GD. Associations of measures of lung function with insulin resistance and Type 2 diabetes: findings from the British Women's Heart and Health Study. Diabetologia. 2004;47(2):195-203.

25. Leonidou L, Mouzaki A, Michalaki M, et al. Cytokine production and hospital mortality in patients with sepsis-induced stress hyperglycemia. J Infect. 2007;55(4):340-346.

26. Koskela HO, Salonen PH, Romppanen J, Niskanen L. A history of diabetes but not hyperglycaemia during exacerbation of obstructive lung disease has impact on long-term mortality: a prospective, observational cohort study. BMJ Open. 2015;5(1):e006794.

27. Moretti M, Cilione C, Tampieri A, Fracchia C, Marchioni A, Nava S. Incidence and causes of non-invasive mechanical ventilation failure after initial success. Thorax. 2000;55(10):819-825.

28. Rabe KF, Hurd S, Anzueto A, et al. Global strategy for the diagnosis, management, and prevention of chronic obstructive pulmonary disease: GOLD executive summary. Am J Respir Crit Care Med. 2007;176(6): 532-555.

29. Breakey S, Sharp SJ, Adler AI, Challis BG. Glucocorticoid-induced hyperglycaemia in respiratory disease: a systematic review and metaanalysis. Diabetes Obes Metab. 2016;18(12):1274-1278.

30. Baker JM, Pace HA, Ladesich JB, Simon SD. Evaluation of the impact of corticosteroid dose on the incidence of hyperglycemia in hospitalized patients with an acute exacerbation of chronic obstructive pulmonary disease. Hosp Pharm. 2016;51(4):296-304.

31. Koskela HO, Salonen PH, Niskanen L. Hyperglycaemia during exacerbations of asthma and chronic obstructive pulmonary disease. Clin Respir J. 2013;7(4):382-389.

32. Habib G, Dar-Esaif Y, Bishara H, et al. The impact of corticosteroid treatment on hemoglobin A1C levels among patients with type-2 diabetes with chronic obstructive pulmonary disease exacerbation. Respir Med. 2014;108(11):1641-1646.

33. Li CI, Li TC, Liu CS, et al. Extreme values of hemoglobin a1c are associated with increased risks of chronic obstructive pulmonary disease in patients with type 2 diabetes: a competing risk analysis in national cohort of Taiwan diabetes study. Medicine (Baltimore). 2015; 94(1):e367.

34. Wei L, MacDonald TM, Walker BR. Taking glucocorticoids by prescription is associated with subsequent cardiovascular disease. Ann Intern Med. 2004;141(10):764-770.

35. Krinsley JS, Fisher M. The diabetes paradox: diabetes is not independently associated with mortality in critically ill patients. Hospl Pract (1995). 2012;40(2):31-35.

36. Krinsley JS, Egi M, Kiss A, et al. Diabetic status and the relation of the three domains of glycemic control to mortality in critically ill patients: an international multicenter cohort study. Crit Care. 2013;17(2):R37.

37. Egi M, Bellomo R, Stachowski E, et al. The interaction of chronic and acute glycemia with mortality in critically ill patients with diabetes. Crit Care Med. 2011;39(1):105-111.

38. Patel A, MacMahon S, Chalmers J, et al. Intensive blood glucose control and vascular outcomes in patients with type 2 diabetes. $N$ Engl J Med. 2008;358(24):2560-2572.

39. Gerstein HC, Miller ME, Byington RP, et al. Effects of intensive glucose lowering in type 2 diabetes. $N$ Engl J Med. 2008;358(24): 2545-2559. 
40. Krinsley JS, Meyfroidt G, van den Berghe G, Egi M, Bellomo R. The impact of premorbid diabetic status on the relationship between the three domains of glycemic control and mortality in critically ill patients. Curr Opin Nutr Metab Care. 2012;15(2):151-160.

41. Wright RJ, Frier BM. Vascular disease and diabetes: is hypoglycaemia an aggravating factor? Diabetes Metab Res Rev. 2008;24(5):353-363.

42. Wright RJ, Newby DE, Stirling D, Ludlam CA, Macdonald IA, Frier BM. Effects of acute insulin-induced hypoglycemia on indices of inflammation: putative mechanism for aggravating vascular disease in diabetes. Diabetes Care. 2010;33(7):1591-1597.

43. Kasirye Y, Simpson M, Mamillapalli CK, Epperla N, Liang H, Yale SH. Association between blood glucose level and outcomes in patients hospitalized for acute exacerbation of chronic obstructive pulmonary disease. WMJ. 2013;112(6):244-249.
44. Pu LJ, Shen Y, Lu L, Zhang RY, Zhang Q, Shen WF. Increased blood glycohemoglobin A1c levels lead to overestimation of arterial oxygen saturation by pulse oximetry in patients with type 2 diabetes. Cardiovasc Diabetol. 2012;11:110.

45. Yamada T, Shojima N, Noma H, Yamauchi T, Kadowaki T. Glycemic control, mortality, and hypoglycemia in critically ill patients: a systematic review and network meta-analysis of randomized controlled trials. Intensive Care Med. 2017;43(1):1-15.

\section{Publish your work in this journal}

The International Journal of COPD is an international, peer-reviewed journal of therapeutics and pharmacology focusing on concise rapid reporting of clinical studies and reviews in COPD. Special focus is given to the pathophysiological processes underlying the disease, intervention programs, patient focused education, and self management protocols.

\section{Dovepress}

This journal is indexed on PubMed Central, MedLine and CAS. The manuscript management system is completely online and includes a very quick and fair peer-review system, which is all easy to use. Visit http://www.dovepress.com/testimonials.php to read real quotes from published authors.

Submit your manuscript here: http://www.dovepress.com/international-journal-of-chronic-obstructive-pulmonary-disease-journal 